\title{
Burnout among Plastic Surgery Residents in India: An Observational Study
}

\author{
Nikhil Panse ${ }^{1}$ Smita Panse ${ }^{2}$ Swaminathan Ravi ${ }^{1}$ Hemant Mankar ${ }^{1}$ Ankur Karanjkar ${ }^{1}$ \\ Parag Sahasrabudhe ${ }^{1}$
}

${ }^{1}$ Department of Plastic Surgery, B. J. Government Medical College \& Sassoon Hospital, Pune, India

2Department of Psychiatry, PCMC's Post Graduate Institute \& YCM

Hospital, Pimpri, Pune, India

Address for correspondence Nikhil Panse, MCh, DNB, Department of Plastic Surgery, B. J. Government Medical College \& Sassoon Hospital, Jai Prakash Narayan Road, Near Pune Railway Station, Pune, 411001, India (e-mail: nikhil.panse@rediffmail.com).

Indian J Plast Surg:2020;53:387-393

\begin{abstract}
Keywords

- burnout

- professional burnout

- workplace stress

- occupational burnout

- plastic surgery

Introduction Burnout syndrome can be defined as emotional exhaustion, depersonalization, and perceived lack of personal accomplishment, all of which lead to decreased effectiveness at work. The Medscape burnout and depression report of 2018 suggests that the burnout range across various specialties ranges from 23 to $48 \%$. There are no studies to assess the burnout among plastic surgery residents in India. This study is an attempt to assess the same.

Materials and Methods An online survey was conducted in March and April 2019 for plastic surgery residents across India. Various parameters including those related to gender, year of the curriculum, hobbies, exercise, and marital status were assessed. There were multiple sections in the survey, which included the demographic details, stress-related variables, and the abbreviated Maslach Burnout Inventory. The abbreviated Maslach Burnout Inventory is a validated scale that has been used to assess the burnout among plastic surgery residents in India. The three subscales, emotional exhaustion, depersonalization, and personal accomplishment were measured on a Likert scale. Univariable and multivariable analysis of factors associated with burnout was performed.

Results Of the 185 respondents, $48.4 \%$ experienced moderate-to-high burnout. Of these, $25 \%(n=46)$ were above the 75 th centile of the overall burnout score, indicating severe burnout. Insufficient faculty involvement, insufficient time allotted for formalized teaching, conflict with colleagues, and lack of adequate support staff correlated with resident burnout on multivariate analysis. Residents who pursued their hobbies or performed physical activities for exercise had significantly lesser burnout.

Conclusion The incidence of burnout in plastic surgery residents surveyed in our study was $48.4 \%$. The faculty of the departments and the residents themselves, as well as the governing bodies, all have a role to play to address the issue of burnout among residents. Dedicated and persistent efforts toward improving physical and psychological well-being of plastic surgery residents will positively impact not only the well-being of the residents but also the quality of patient care.
\end{abstract}

published online

November 24, 2020
DOI https://doi.org/

$10.1055 / \mathrm{s}-0040-1719238$

ISSN 0970-0358. (c) 2020. Association of Plastic Surgeons of India.

This is an open access article published by Thieme under the terms of the Creative Commons Attribution-NonDerivative-NonCommercial-License, permitting copying and reproduction so long as the original work is given appropriate credit. Contents may not be used for commercial purposes, or adapted, remixed, transformed or built upon. (https://creativecommons.org/licenses/by-nc-nd/4.0/) Thieme Medical and Scientific Publishers Pvt. Ltd., A-12, 2nd Floor, Sector 2, Noida-201301 UP, India 


\section{Introduction}

Occupational burnout in the medical fraternity is an unwanted outcome of chronic workplace stress. Burnout syndrome can be defined as emotional exhaustion, depersonalization, and perceived lack of personal accomplishment, all of which lead to decreased effectiveness at work. ${ }^{1}$ The ramifications of the burnout syndrome can be multiple and devastating at a personal as well as at a professional level. At a personal level, it can lead to depression, anxiety, broken relationships, addictions, and even suicide in extreme conditions. ${ }^{2}$ At a professional level, it may lead to a difficult interpersonal relationship with patients and coworkers, diminished commitment to patient care, medical errors, poor judgment in decision-making regarding patient care, and many more. ${ }^{3}$

The Medscape National Physician Burnout and Depression Report of 2018 suggests that burnout range across various specialties is from $23 \%$ to $48 \%$, with general surgeons at $43 \%$ burnout. ${ }^{4}$ In general, surgery trainees are at a high risk of burnout because residency training is intense, involves long working hours, and is stressful. The trainees have to cope up with clinical workload with unpredictable work timings. ${ }^{5,6}$ Plastic surgery trainees in India have their distinctive set of problems such as considerable emergency work, a wide spectrum of specialty training with extensive curriculum, and so on. There have been very few studies conducted globally to assess the burnout in plastic surgery residents. ${ }^{7-10}$ This study was performed to assess the burnout in plastic surgery residents across India.

\section{Material and Methods}

An online survey to assess burnout was conducted in plastic surgery residents across India in March and April 2019. The survey was conducted after Institutional Ethics Committee clearance and was totally anonymous. There were multiple sections in the survey, which included the demographic details, stress-related variables, and the abbreviated Maslach Burnout Inventory (aMBI). Data were collected in Google forms and then transferred to Excel sheet and analyzed.

The aMBI has nine item scales for assessing burnout, and its validity and reliability has already been established.6,11 It has three subscales: emotional exhaustion "EE" (emotional depletion due to job demand and continuous work-related stress), depersonalization "DP"(impersonal response toward the recipient of service), and personal accomplishment "PA" (the degree of personal competence, achievement, and satisfaction with work). Each subscale is assessed by three items. For each item, there is a 7-point Likert scale, which ranges from never (0) to every day (6). The score for each item was summed up for each resident. For EE and DP, a higher score means greater burnout. This is inverse for PA. The score of each subscale could range from a minimum 0 to maximum 18. High scores of EE and DP and low score of PA indicate a higher level of burnout.
As described by Shaikh et $a l,{ }^{12}$ we combined the scores of EE and DP to calculate the overall burnout score. For EE and DP, subscale score of 0 to 9 was regarded as "no-to-low burnout" and subscale score of 10 to 18 was regarded as "moderate-to-severe burnout." It was opposite for PA because higher PA scores indicate lesser burnout. ${ }^{6}$ Frequencies and percentages were calculated for various variables.

\section{Statistical Analysis}

For the analysis, burnout scores were categorized as $<19$ or $\geq 19$. Categorical variables were summarized using percentages and frequencies and compared using Fisher's exact Test. Univariable analysis and multivariable modelling were performed on those variables that were significant. The significance level was set at $p<0.05$.

Logistic regression analysis was used to find the association between burnout and factors influencing it. The logit link function, the calculated odds ratio (OR), and a 95\% confidence interval for the OR were considered to determine whether the association between burnout and the factors was statistically significant. The significance level was again set at $p<0.05$.

\section{Results}

There were in all 185 responses from various states ranging from Kashmir to Kerala. Of the responders, 88.1\% opted for plastic surgery by choice. However, on the subsequent question of whether they would opt for plastic surgery again if given a choice, only $74.5 \%$ responded positively. On the subsequent question of whether they would like to pursue the curriculum in their own institute, the percentage further dropped to $45.7 \%$. Year of training was identified as an independent factor for burnout, with $63 \%$ of first-year residents experiencing moderate-to-high burnout, which dropped to $43 \%$ in the second year of training and $41 \%$ in the third year of training. Of the female trainees, $52 \%$ were analyzed to be experiencing moderate-to-high burnout, which was comparable to $47 \%$ of male trainees experiencing moderate-to-high burnout. The overall burnout scores as per the aMBI were plotted on a bar graph ( - Fig. 1). However, this difference was not statistically significant.

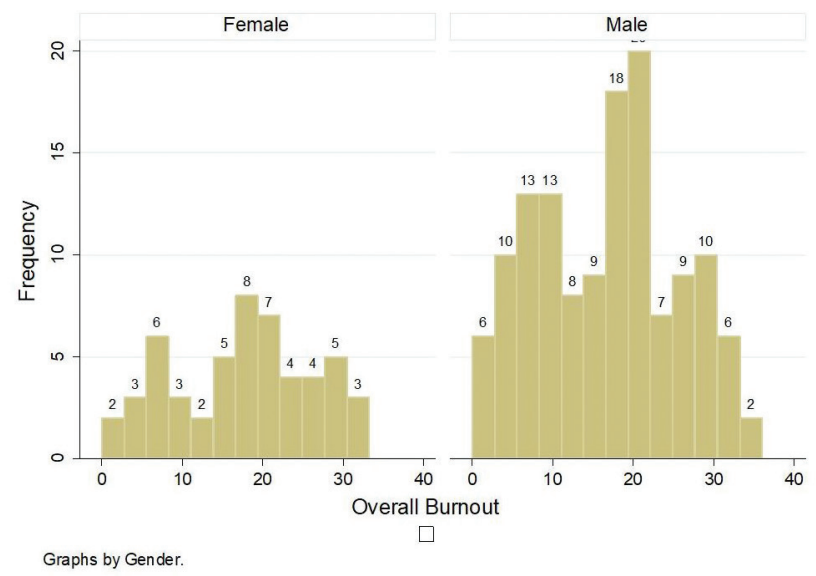

Fig. 1 Gender distribution of responders. 
Attempt was made to identify the common stressors by asking participants to respond to general statements regarding the stressors; $33 \%$ responders were stressed "a lot" because of a large overall volume of work and 3.3\% participants were stressed "a lot" because of too less overall volume of work. Having a large volume of work was an independent factor for burnout, whereas not having enough work did not correlate with resident burnout. Overall, $77.3 \%$ of the responders were dealing with variable levels of stress because of angry or blaming patients, and $49.7 \%$ responders were stressed "a lot" because of poor pay scale. However, this factor did not correlate with higher levels of burnout among residents. Insufficient faculty involvement, insufficient time allotted for formalized teaching, conflict with colleagues, and lack of adequate support staff correlated with resident burnout. Residents who pursued their hobbies or performed physical activities for exercise had significantly lesser burnout. Details of univariable analysis of factors associated with burnout are mentioned in - Table 1. Details of multivariable model for independent factors associated with burnout are mentioned in - Table 2.

We found that $25 \%$ of responders had moderate-to-high burnout regarding DP, which rose to $64 \%$ on the questions relating to EE. However, $90 \%$ of the trainees had a no to low burnout score in PA.

For EE and DP, a higher score means greater burnout. This is inverse for PA. Overall, $48.4 \%$ of candidates experienced moderate-to-high burnout. Of these, $25 \%(n=46)$ were above the 75th centile of the overall burnout score, indicating severe burnout ( - Table 3 ).

\section{Discussion}

The analysis of burnout in medicine, students, physicians, and surgeons has been studied to a great extent. ${ }^{5,11,13,14}$ It is well known that burnout is the highest during residency training and subsequently decreases with increasing seniority. ${ }^{13,15}$ However, studies in plastic surgery are very less, and to the best of our knowledge, this is the first of its kind study to assess burnout in plastic surgery residents across India. Plastic surgery training in India has its own set of challenges: very few training institutes, a long grueling path to be a plastic surgery trainee, considerable emergency work, and a wide spectrum of specialty training with limited exposure to the entire spectrum at most places to name a few.

As residents in plastic surgery, there is constant exposure to an environment of traumatic events requiring long-term and complex wound care and management. It has been shown that exposure to chronic and critically ill patients has a higher risk of burnout as compared with other disciplines of medicine. ${ }^{16}$

Ribeiro et $\mathrm{al}^{8}$ performed a systematic literature review and meta-analysis to analyze the prevalence of burnout among plastic surgeons and residents in plastic surgery. Their study showed burnout prevalence rates of $32.32 \%$ among plastic surgeons and $36.66 \%$ among residents. They inferred that personal characteristics do not seem to have much influence on burnout as the characteristics of employment are essentially similar, both in plastic surgeons ${ }^{17-19}$ and residents in plastic surgery. ${ }^{16,20}$

Chaput et $\mathrm{al}^{7}$ in their study of plastic surgery residents in France showed that their burnout level was approximately $28.8 \%$. They noted that the personal characteristics including age, marital status, and involvement in sports activities or leisure showed less influence on the development of burnout. The factors with the highest positive correlation were professional and included being in the first year of training, being dissatisfied with career plans, and working in units not visited weekly by senior surgeons or where staff meetings do not occur.

Aldrees et $\mathrm{al}^{9}$ conducted a national survey among plastic surgery residents in Saudi Arabia. They noted that approximately half of plastic surgery trainees in the Kingdom of Saudi Arabia had signs of professional burnout. However, only $5 \%$ were dissatisfied with plastic surgery specialty as a career, and $69 \%$ would choose the same specialty again. They noted that workload was not found to play a significant role in the development of burnout.

The burnout rates of plastic surgery residents in India are comparable to those of the Kingdom of Saudi Arabia and are higher than that of France. The burnout rates are around 50\% in India, 50\% in Saudi Arabia, and 28.5\% in France. The studies by both Chaput et $\mathrm{al}^{7}$ and Aldrees el $\mathrm{al}^{9}$ have used the Maslach Burnout Inventory. We have used the aMBI for the analysis of burnout.

Our training programs in India at most centers are not structured in a fashion to have fixed 8-hour duties for residents. Our training program is structured in a fashion that the on-call emergency duties and the inpatient duties decrease as the resident progresses from the first year to the third year. Thus, the burden of the collective years of training is balanced with the progressive decrease in workload from the first year to the third year of residency. That also might be an important reason for increased burnout in the first-year residents as compared with second- and third-year residents, as observed in our study.

It also has been documented that the most susceptible for burnout appear to be those doctors who are most dedicated, conscientious, responsible, and motivated. ${ }^{18}$ Thus, the same characters that define a good surgeon or a good resident also place them at a greater risk of burnout. ${ }^{18,19,21}$ It would be prudent to assume that the residents who are pursuing super specialty training are a dedicated lot and might be at a higher risk of burnout.

Our survey included an open-ended question: "Any other causes of stress at your workplace which you would like to mention?" The responses were varied and ranged from food, language, accommodation, duty hours, and less pay scale, among others. Faculty and social environment were also among the causes of stress mentioned. The social environment of the workplace and the organizational structure are very important and particularly relevant contributing factors to burnout and compassion fatigue. ${ }^{1}$ Unstable work routine, high workload, reduced time for family and leisure, and difficulty in seeking professional help are also the factors that 
Table 1 Univariable analysis of factors related to resident burnout

\begin{tabular}{|c|c|c|c|c|c|}
\hline \multirow[t]{2}{*}{ Characteristics } & \multirow[t]{2}{*}{ Responses } & \multicolumn{2}{|c|}{ Burnout } & \multirow[t]{2}{*}{ OR $(95 \% \mathrm{Cl})$} & \multirow[t]{2}{*}{$p$-Value } \\
\hline & & $<19, n=95$ & $\geq 19, n=90$ & & \\
\hline \multicolumn{6}{|l|}{ Gender, $n$ (\%) } \\
\hline Female & 52 & $25(48 \%)$ & 27 (52\%) & Ref & - \\
\hline Male & 131 & $70(53 \%)$ & $61(47 \%)$ & $0.81(0.42-1.54)$ & 0.52 \\
\hline \multicolumn{6}{|l|}{ Marital status } \\
\hline Married & 145 & $73(50 \%)$ & $72(50 \%)$ & Ref & - \\
\hline Unmarried & 39 & $21(54 \%)$ & $18(46 \%)$ & $0.87(0.43-1.77)$ & 0.70 \\
\hline \multicolumn{6}{|l|}{ Curriculum } \\
\hline DNB & 23 & $11(48 \%)$ & $12(52 \%)$ & Ref & - \\
\hline MCh & 159 & $82(52 \%)$ & $77(48 \%)$ & $0.86(0.36-2.07)$ & 0.74 \\
\hline \multicolumn{6}{|l|}{ Year of training } \\
\hline First & 57 & $21(36 \%)$ & $36(63 \%)$ & Ref & - \\
\hline Second & 42 & $24(57 \%)$ & $18(43 \%)$ & $0.44(0.19-0.99)$ & 0.047 \\
\hline Third & 80 & $47(59 \%)$ & $33(41 \%)$ & $0.41(0.20-0.82)$ & 0.012 \\
\hline \multicolumn{6}{|c|}{ Opted for plastic surgery by choice? } \\
\hline No & 22 & $12(55 \%)$ & $10(45 \%)$ & Ref & - \\
\hline Yes & 163 & $83(51 \%)$ & 80 (49\%) & $1.16(0.47-2.83)$ & 0.75 \\
\hline \multicolumn{6}{|c|}{ If given an option, will you opt for plastic surgery again? } \\
\hline No & 47 & $23(49 \%)$ & $24(51 \%)$ & Ref & - \\
\hline Yes & 137 & $72(53 \%)$ & $65(47 \%)$ & $0.86(0.45-1.68)$ & 0.67 \\
\hline \multicolumn{6}{|c|}{ Do you pursue any hobbies at least once in $2 \mathrm{wk}$ ? } \\
\hline No & 136 & $56(41 \%)$ & $80(59 \%)$ & Ref & - \\
\hline Yes & 49 & $39(80 \%)$ & $10(20 \%)$ & $0.18(0.08-0.39)$ & $p<0.001$ \\
\hline \multicolumn{6}{|c|}{ Do you perform any physical activities for fitness at least once in $2 \mathrm{wk}$ ? } \\
\hline No & 121 & $53(44 \%)$ & $68(56 \%)$ & Ref & - \\
\hline Yes & 64 & $42(66 \%)$ & $22(34 \%)$ & $0.41(0.22-0.77)$ & 0.005 \\
\hline \multicolumn{6}{|c|}{ Do you have a large volume of work? } \\
\hline Not at all & 12 & $10(83 \%)$ & $2(17 \%)$ & Ref & - \\
\hline Yes & 173 & $85(49 \%)$ & $88(51 \%)$ & $5.18(1.10-24.32)$ & 0.04 \\
\hline \multicolumn{6}{|c|}{ Do you have too less volume of work? } \\
\hline Not at all & 125 & $61(49 \%)$ & $64(51 \%)$ & Ref & - \\
\hline Yes & 60 & $34(57 \%)$ & $26(43 \%)$ & $0.73(0.39-1.35)$ & 0.32 \\
\hline \multicolumn{6}{|c|}{ Do you feel you are poorly paid? } \\
\hline Not at all & 16 & $9(56 \%)$ & $7(44 \%)$ & Ref & - \\
\hline Yes & 169 & $86(51 \%)$ & $83(49 \%)$ & $1.24(0.44-3.49)$ & 0.68 \\
\hline \multicolumn{6}{|c|}{ Any disruption in family life? } \\
\hline Not at all & 10 & $10(100 \%)$ & 0 & Ref & 0.002 \\
\hline Yes & 175 & $85(49 \%)$ & $90(51 \%)$ & Cannot Estimate & \\
\hline \multicolumn{6}{|c|}{ Do you feel there is insufficient formal teaching time? } \\
\hline Not at all & 19 & $16(84 \%)$ & $3(16 \%)$ & Ref & - \\
\hline Yes & 166 & $79(48 \%)$ & $87(52 \%)$ & $5.87(1.65-20.92)$ & 0.006 \\
\hline \multicolumn{6}{|c|}{ Is the faculty interested in teaching? } \\
\hline Not at all & 66 & $46(70 \%)$ & $20(30 \%)$ & Ref & - \\
\hline Yes & 119 & $49(41 \%)$ & $70(59 \%)$ & $3.29(1.73-6.23)$ & $p<0.001$ \\
\hline
\end{tabular}


Table 1 (Continued)

\begin{tabular}{|c|c|c|c|c|c|}
\hline \multirow[t]{2}{*}{ Characteristics } & \multirow[t]{2}{*}{ Responses } & \multicolumn{2}{|c|}{ Burnout } & \multirow[t]{2}{*}{ OR (95\% Cl) } & \multirow[t]{2}{*}{$p$-Value } \\
\hline & & $<19, n=95$ & $\geq 19, n=90$ & & \\
\hline \multicolumn{6}{|c|}{ Any conflict with colleagues? } \\
\hline Not at all & 51 & $39(76 \%)$ & $12(24 \%)$ & Ref & - \\
\hline Yes & 134 & $56(42 \%)$ & $78(58 \%)$ & $4.53(2.18-9.42)$ & $p<0.001$ \\
\hline \multicolumn{6}{|c|}{ Is there a lack of support staff? } \\
\hline Not at all & 33 & $22(67 \%)$ & $11(33 \%)$ & Ref & - \\
\hline Yes & 152 & $73(48 \%)$ & 79 (52\%) & $2.16(0.98-4.77)$ & 0.06 \\
\hline \multicolumn{6}{|c|}{ Is there inadequate infrastructure? } \\
\hline Not at all & 33 & $18(55 \%)$ & $15(45 \%)$ & Ref & - \\
\hline Yes & 152 & 77 (51\%) & 75 (49\%) & $1.17(0.55-2.49)$ & 0.69 \\
\hline \multicolumn{6}{|c|}{ Is the quality of accommodation poor? } \\
\hline Not at all & 48 & $18(38 \%)$ & $30(63 \%)$ & Ref & - \\
\hline Yes & 137 & 77 (56\%) & $60(44 \%)$ & $0.47(0.24-0.92)$ & 0.03 \\
\hline
\end{tabular}

Abbreviations: DNB, Diplomate in National Board; MCh, Magister of Chirurgiae.

Table 2 Multivariable model for independent factors associated with burnout

\begin{tabular}{|c|c|c|c|c|}
\hline \multirow[t]{2}{*}{ Characteristics } & \multicolumn{2}{|c|}{ Univariable analysis } & \multicolumn{2}{|c|}{ Multivariable analysis } \\
\hline & OR $(95 \% \mathrm{Cl})$ & $p$-Value & OR $(95 \% \mathrm{Cl})$ & $p$-Value \\
\hline \multicolumn{5}{|l|}{ Year of training } \\
\hline First & Ref & - & Ref & - \\
\hline Second & $0.44(0.19-0.99)$ & 0.047 & $0.43(0.16-1.18)$ & 0.10 \\
\hline Third & $0.41(0.20-0.82)$ & 0.012 & $0.36(0.15-0.85)$ & 0.02 \\
\hline \multicolumn{5}{|c|}{ Do you pursue any hobbies at least once in 2 wk? } \\
\hline No & Ref & - & Ref & - \\
\hline Yes & $0.18(0.08-0.39)$ & $p<0.001$ & $0.18(0.07-0.85)$ & $\mathrm{p}<0.001$ \\
\hline \multicolumn{5}{|c|}{ Do you perform any physical activities for fitness at least once in $2 \mathrm{wk} ?$} \\
\hline No & Ref & - & Ref & - \\
\hline Yes & $0.41(0.22-0.77)$ & 0.005 & $0.90(0.38-2.10)$ & 0.82 \\
\hline \multicolumn{5}{|c|}{ Do you have a large volume of work? } \\
\hline Not at all & Ref & - & Ref & - \\
\hline Yes & $5.18(1.10-24.32)$ & 0.04 & $5.46(0.70-42.44)$ & 0.11 \\
\hline \multicolumn{5}{|c|}{ Do you feel there is insufficient formal teaching time? } \\
\hline Not at all & Ref & - & Ref & - \\
\hline Yes & $5.87(1.65-20.92)$ & 0.006 & $5.34(1.17-24.32)$ & 0.03 \\
\hline \multicolumn{5}{|c|}{ Is the faculty interested in teaching? } \\
\hline Not at all & Ref & - & Ref & - \\
\hline Yes & $3.29(1.73-6.23)$ & $\mathrm{p}<0.001$ & $2.32(1.01-5.35)$ & 0.047 \\
\hline \multicolumn{5}{|c|}{ Any conflict with colleagues? } \\
\hline Not at all & Ref & - & Ref & - \\
\hline Yes & $4.53(2.18-9.42)$ & $p<0.001$ & $4.25(1.74-10.34)$ & 0.001 \\
\hline \multicolumn{5}{|c|}{ Is there a lack of support staff? } \\
\hline Not at all & Ref & - & Ref & - \\
\hline Yes & $2.16(0.98-4.77)$ & 0.06 & $1.61(0.60-4.29)$ & 0.34 \\
\hline \multicolumn{5}{|c|}{ Is the quality of accommodation poor? } \\
\hline Not at all & Ref & - & Ref & - \\
\hline Yes & $0.47(0.24-0.92)$ & 0.03 & $0.38(0.15-0.93)$ & 0.03 \\
\hline
\end{tabular}

Abbreviations: $\mathrm{Cl}$, confidence interval; OR, odds ratio. 
Table 3 aMBI analysis

\begin{tabular}{|l|l|l|}
\hline $\begin{array}{l}\text { Scoring } \\
\text { parameter }\end{array}$ & $\begin{array}{l}\text { No-to-low } \\
\text { burnout (0-9) }\end{array}$ & $\begin{array}{l}\text { Moderate-to-high } \\
\text { burnout (10-18) }\end{array}$ \\
\hline DP & $137(74.1 \%)$ & $48(25.9 \%)$ \\
\hline EE & $67(36.2 \%)$ & $118(63.8 \%)$ \\
\hline PA & $168(90.8 \%)$ & $17(9.2 \%)$ \\
\hline $\begin{array}{l}\text { Overall } \\
\text { burnout (aMBI) }\end{array}$ & $95(51.6 \%)$ & $90(48.4 \%)$ \\
\hline
\end{tabular}

predispose to burnout. ${ }^{11,15-19,22-24}$ In addition to the deleterious effects on the residents themselves, it can lead to deterioration of the quality of care and worsening of patient outcomes. The social environment and the organizational structure of the department are largely modifiable and depend on the faculty of the department. Introspection is necessary to modify it so as to provide a more suitable and cohesive workplace environment to the residents in plastic surgery.

It is also important to note here that early and regular assessment of burnout among residents is essential, mainly because it is a reversible phenomenon, and can be rectified if due care is taken at the proper time. ${ }^{24}$ The American Society of Plastic Surgeons on their website has links to wellness resources as well as a suicide prevention lifeline. ${ }^{25}$ After the unfortunate suicide of a resident in Nair Hospital in 2019, the Indian Medical Association has launched an initiative named D4D (Doctors for Doctors) to address burnout and mental health challenges faced by our residents and doctors. ${ }^{26}$ Support options and groups like these should be encouraged, where residents can interact with professionals and can be assisted to identify burnout and cope with it. ${ }^{21}$ Furthermore, psychological assessments can be used as a tool for screening and prevention of burnout among residents of plastic surgery in India. ${ }^{9,24}$

Each one of us including the residents will have to deal with stressful times in our personal and professional lives. The faculty should attempt to provide a cohesive and amicable work environment to the residents. The residents too must cultivate habits and try to maintain a work-life balance. They must seek professional help when they notice signs of burnout. The Association of Plastic Surgeons of India, the bodies of medical education in India including the National Medical Comission, the National Board of Examinations, and other health universities across India can set strategies and issue advisories to decrease the impact of burnout on plastic surgery residents in India.

\section{Limitations}

Our study has some limitations, and the results should be interpreted in the context of these limitations. India is a huge country with residents migrating to different states to pursue higher education. Responses may vary considering variations in training environment, language barriers, personality, working hours, and even pay scale, which vary from state to state. Surveys like these have the inherent limitation of interpretation bias, social desirability bias, and recall bias.
However, the design of the survey and highly representative sample size across India is unlikely to have caused any impact of findings of this study.

\section{Conclusion}

There is a remarkably high rate of burnout among plastic surgery residents in India. Overall, $48.4 \%$ of candidates experienced moderate-to-high burnout. Of these, 25\% $(n=46)$ were above the 75 th centile of the overall burnout score, indicating severe burnout. The scores are higher for $\mathrm{EE}$ and DP and lower for PA.

Given that burnout has got significantly deleterious effects on the overall professional and personal well-being of the residents and may affect patient care too, burnout must be addressed on an urgent basis. Resources must be directed to address burnout on different fronts including prevention, identification, diagnosis, and treatment.

Dedicated and persistent efforts toward improving physical and psychological well-being of plastic surgery residents will positively impact not only the well-being of the residents but also the quality of patient care.

\section{Conflict of Interest}

None declared.

\section{Acknowledgments}

We would like to acknowledge Dr. Nikhil Gupte for assistance with statistical analysis.

\section{References}

1 Maslach C, Jackson SQ Leiter MP, Maslach Burnout Inventory. 3rd ed. Palo Alto, CA: Consulting Psychologists Press; 1996

2 Stehman CR, Testo Z, Gershaw RS, Kellogg AR. Burnout, drop out, suicide: physician loss in emergency medicine, part I. West J Emerg Med 2019;20(3):485-494

3 Green A, Duthie HL, Young HL, Peters TJ. Stress in surgeons. Br J Surg 1990;77(10):1154-1158

4 Medscape National Physician Burnout \& Depression Report. Available at: https://www.staging.medscape.com/slideshow/ 2018-lifestyle-burnout-depression-6009235. Accessed January 18,2018

5 Shanafelt TD, Balch CM, Bechamps GJ, et al. Burnout and career satisfaction among American surgeons. Ann Surg 2009; 250(3):463-471

6 Shanafelt TD, Balch CM, Bechamps G, et al. Burnout and medical errors among American surgeons. Ann Surg 2010; 251(6):995-1000

7 Chaput B, Bertheuil N, Jacques J, et al. Professional burnout among plastic surgery residents: can it be prevented? Outcomes of a national survey. Ann Plast Surg 2015;75(1):2-8

8 Ribeiro RVE, Martuscelli OJD, Vieira AC, Vieira CF. Prevalence of burnout among plastic surgeons and residents in plastic surgery: a systematic literature review and meta-analysis. Plast Reconstr Surg Glob Open 2018;6(8):e1854

9 Aldrees T, Hassouneh B, Alabdulkarim A, et al. Burnout among plastic surgery residents. National survey in Saudi Arabia. Saudi Med J 2017;38(8):832-836

10 Shanafelt TD, Balch CM, Dyrbye L, et al. Special report: suicidal ideation among American surgeons. Arch Surg 2011; 146(1):54-62 
11 Riley MR, Mohr DC, Waddimba AC. The reliability and validity of three-item screening measures for burnout: evidence from group-employed health care practitioners in upstate New York. Stress Health 2018;34(1):187-193

12 Shaikh AA, Shaikh A, Kumar R, Tahir A. Assessment of burnout and its factors among doctors using the abbreviated Maslach burnout inventory. Cureus 2019;11(2):e4101

13 Upton D, Mason V, Doran B, Solowiej K, Shiralkar U, Shiralkar S. The experience of burnout across different surgical specialties in the United Kingdom: a cross-sectional survey. Surgery 2012;151(4):493-501

14 Campbell DA Jr, Sonnad SS, Eckhauser FE, Campbell KK, GreenfieldLJ.Burnoutamong Americansurgeons.Surgery2001; 130(4):696-702, discussion 702-705

15 Golub JS, Johns MM III, Weiss PS, Ramesh AK, Ossoff RH. Burnout in academic faculty of otolaryngology-head and neck surgery. Laryngoscope 2008;118(11):1951-1956

16 Qureshi HA, Rawlani R, Mioton LM, Dumanian GA, Kim JYS, Rawlani V. Burnout phenomenon in U.S. plastic surgeons: risk factors and impact on quality of life. Plast Reconstr Surg 2015; 135(2):619-626

17 Balch CM, Freischlag JA, Shanafelt TD. Stress and burnout among surgeons: understanding and managing the syndrome and avoiding the adverse consequences. Arch Surg 2009;144(4): 371-376

18 Shanafelt T. A career in surgical oncology: finding meaning, balance, and personal satisfaction. Ann Surg Oncol 2008; 15(2):400-406
19 Gabbard GO. The role of compulsiveness in the normal physician. JAMA 1985;254(20):2926-2929

20 Toker S, Biron M. Job burnout and depression: unraveling their temporal relationship and considering the role of physical activity. J Appl Psychol 2012;97(3):699-710

21 Haik J, Brown S, Liran A, et al. Burnout and compassion fatigue: prevalence and associations among Israeli burn clinicians. Neuropsychiatr Dis Treat 2017;13:1533-1540

22 Balch CM, Shanafelt TD, Sloan JA, Satele DV, Freischlag JA. Distress and career satisfaction among 14 surgical specialties, comparing academic and private practice settings. Ann Surg 2011;254(4):558-568

23 Streu R, Hansen J, Abrahamse P, Alderman AK. Professional burnout among US plastic surgeons: results of a national survey. Ann Plast Surg 2014;72(3):346-350

24 Dyrbye LN, Shanafelt TD, Balch CM, Satele D, Sloan J, Freischlag J. Relationship between work-home conflicts and burnout among American surgeons: a comparison by sex. Arch Surg 2011;146(2):211-217

25 American society of Plastic surgeons wellness resources. Available at: https://www.plasticsurgery.org/for-medical-professionals/resources/wellness-resources. Accessed June 21, 2020

26 Doctors 4 doctors initiative by the IMA. Available at: https:// medicaldialogues.in/doctors-4-doctors-ima-launches-initiative-to-address-mental-health-issues-reduce-suicide-incidents\#: : text=New\%20Delhi\%3A\%20The\%20Indian\%20 Medical,suicide\%20among\%20residents\%20and\%20clinicians. Accessed June 21, 2020 